\title{
Sports Betting-Motivated Corruption in Australia: An Under-Studied Phenomenon
}

\author{
Reynald Lastra \\ School of Criminology and Criminal Justice, Griffith University \\ 176 Messines Ridge Road, Mt Gravatt Qld 4122, Australia \\ E-mail: reynald.lastra@griffithuni.edu.au \\ Peter Bell (Corresponding author) \\ School of Criminology and Criminal Justice, Griffith University \\ 176 Messines Ridge Road, Mt Gravatt Qld 4122, Australia \\ Tel: 61-7-3735-1131Ｅ-mail: p.bell@griffith.edu.au

\section{Christine Bond} \\ School of Criminology and Criminal Justice, Griffith University \\ 176 Messines Ridge Road, Mt Gravatt Qld 4122, Australia \\ Tel: 61-7-555-27040 E-mail: c.bond@griffith.edu.au
}

Received: November 11, 2015 Accepted: December 8, 2015 Published: January 4, 2016

doi:10.5296/ijssr.v4i1.8563 URL: http://dx.doi.org/10.5296/ijssr.v4i1.8563

\begin{abstract}
With the continual rise of gambling methods there is a need to better understand sports betting-motivated corruption in the Australian context. This literature review highlights seven predominant themes: the Australian gambling culture, betting opportunities available, the threat of sports betting to the integrity of sport, corruption in sport, involvement of transnational organized crime groups in sports corruption, the theoretical perspectives used in sports corruption research, and anti-corruption strategies which are important in the prevention and law enforcement of this criminal behavior. The review identifies significant gaps in existing knowledge surrounding sports betting-motivated corruption, highlighting the need for further research in this area.
\end{abstract}


Keywords: corruption, sports betting, gambling, law enforcement, sports integrity

\section{Introduction}

Gambling, also known as 'gaming', is a popular recreational activity inherent in various cultures all over the world, particularly in Australia (Pinto \& Wilson, 1990), that involves betting something of value such as money on an event such as a game where its result is random and based on chance (George \& Chima, 2014). With sport having a long association with gambling it is no surprise that sports betting-motivated corruption is becoming a topic for discussion, with gambling in particular being found to have a negative influence on sport integrity (Forrest \& Simmons, 2003). This review considered a wide range of sources, including scholarly articles, government reports, organizational reports, books and other relevant sources, to explore current knowledge on the phenomenon, particularly in an Australian context. In doing so the review identified seven predominant themes discussed in this paper and identified a need for further research on the topic.

\subsection{The Australian Gambling Culture}

In support of the notion that Australia is a gambling nation (Delfabbro \& King, 2012) reported that up to $80 \%$ of Australians will participate in gambling at least once in their lifetime. Furthermore, $\mathrm{H} 2$ Gambling Capital ranked Australians as the biggest gamblers in the world in 2013 when measured in terms of loss per capita (The Economist, 2014). Overall, the total expenditure on gambling was estimated at approximately AU\$19 billion for the period of 2008-2009 (Productivity Commission, 2010).

Impacting on Australia's gambling culture are the various avenues of gambling being offered, such as lotteries, electronic gaming machines or 'pokies', betting (racing and sport), and table games (Worthington, Brown, Crawford, \& Pickernell, 2007). These forms of gambling are offered within two types of gambling environments: interactively and in-person (Gainsbury, 2014). Interactive gambling involves the use of the Internet to access gambling activities through interactive media such as computers, smart phones, tablets and smart televisions (Gainsbury et al., 2015). Gambling in person involves land-based outlets and placing bets over the telephone directly with bookmakers. Whilst gambling in person is still a popular method of gaming, interactive gambling is growing rapidly and is predicted to overtake the traditional method of gambling in person (Gainsbury, 2014).

\section{Sports Betting}

The relationship between gambling and sport has always existed and, historically, many sports have been affected and influenced by the gambling industry. In the eighteenth century betting was a key influence in the development of formal structures in sport (Forrest \& Simmons, 2003). For instance, bookmakers influenced the codification of cricket's rules in 1744 to ensure uniformity in rules across matches, as well as introducing a governing body to resolve disputes on the payment of bets. While this may have been a step forward in cricket and sports in general the presence of gambling has been found to negatively impact the integrity of sport (Forrest \& Simmons, 2003). 


\subsection{The Rise of Sports Betting}

A significant concern surrounding the issue of sport integrity is the exponential growth of the sports betting industry. Since the mid-1990s the development of the Internet and the rise of interactive media have been significant catalysts in the growth of the gambling industry, and more specifically the sports betting trade (Humphreys, 2011; Reiche, 2013). The rapid growth of sports betting can largely be attributed to a readily accessible global betting market (ACC, 2013). Humphreys (2011) proffers that punters are no longer confined to the domestic market and are now able to bet on any number of sports, played anywhere in the world. However, the issue with the global betting market is that punters now have the option to access both unregulated offshore bookmakers and highly-regulated providers who operate within the domestic market (ACC, 2013). The implications of this are that unregulated markets could be used to facilitate criminal activity, which in turn negatively affects the integrity of sport in Australia. This globalization of sports betting, however, has led to its exponential growth, with sports betting being recognized as the fastest growing sector of the Australian gambling market. For instance, the Australian Crime Commission (ACC) (2013) states that sports betting in Australia alone has increased by $278 \%$ from AU\$880 million in 2000-01 to AU\$3.3 billion in 2010-11.

\subsubsection{Sports Sponsorship and Sports Betting}

Supplementary to the growth of sports betting is the sponsorship of sport by betting agencies (Hing, Vitartas, \& Lamont, 2013). Research on sports sponsorship suggests that the dependency of sport on income provided by the betting industry is increasing. For instance, a study of sports sponsorship among national, regional and local club-level sports in New Zealand in 2006 found that the gambling industry is the most prominent sponsor of sport at every level from junior to national tiers (Maher, Wilson, Signal, \& Thomson, 2006). Maher et al. (2006) argue that sport sponsorship by betting agencies in turn allows them to associate betting with a popular community-based activity. This creates a positive community response to their organization and its activities. A study conducted by Mason (2005) found that when the public view sponsorship as the reason for a sporting event's existence they are more likely to accept and support the sponsor's products. Hing et al. (2013) state that sports sponsorship by bookmakers and the promotion of their products at matches may be normalizing gambling, as well as fostering gambling problems. Milner, Hing, Vitartas and Lamont (2013) shared a similar position, stating that gambling sponsorship and its heavy marketing strategies are fuelling the growth of sports betting and inadvertently inviting corruption in sports.

\subsubsection{Promotion of Sports Betting}

The promotion of sports betting products through aggressive marketing on television and through social media platforms is another significant factor in the growth of the betting industry (Thomas, Lewis, Duong, \& McLeod, 2012). The degree of sophistication of sports betting-related marketing is much greater than the typical advertising on television and on the Internet. The marketing of betting services during sporting events consists of commercial contracts between a number of stakeholders, including: the betting industry, sporting codes, stadiums, scoreboard operators, broadcasters, and individual clubs (Thomas et al., 2012). A 
study of sports betting advertising during Australian Football League (AFL) matches by Thomas et al. (2012) found that the marketing approaches explored by bookmakers embedded the activity within the game itself by linking sports betting with the spectator's experience and encouraging live betting. The study also found that there was an increase in the amount of positive messages surrounding gambling during matches, with minimal advertising of responsible gambling. The marketing strategies employed by bookmakers clearly targets spectators and, in particular, the most vulnerable demographic to gambling problems, young people (McMullan, Miller, \& Perrier, 2012; Tse et al., 2012).

\subsubsection{Placing a Sports Bet}

As noted, there has been a rise in the betting options available to punters. Traditionally punters were limited to betting on the outcome of a sporting event, but now bets can be placed place on a variety of events that may occur after the game has started or even while it is underway (Forrest, 2012; Palmer, 2014). The International Centre for Sport Security (ICSS) (2014) argues that the Internet has been instrumental in developing an array of betting options, including: betting exchanges, live betting and the opportunity to bet on less publicized sporting events.

The nature of placing a sports bet in Australia has also evolved, including fixed-odds wagers, in-play bets, exotic bets and micro-bets. Fixed-odds wagering involves the bookmaker paying the punter a ratio of the amount wagered if a certain team or athlete wins a match (Schnytzer \& Weinberg, 2008). Additional to placing a bet before a match, in-play (live) betting is an option that enables punters to place a wager during a contest (Boniface, Lacarriere, Verschuuren, \& Tuallon, 2012). For example, during a rugby league match a punter can place a bet on the winning team based upon the current live score. An exotic bet is another type of in-play betting where a wager can be made on a particular situation occurring during a match (VRGF, 2013). For instance, a punter could bet on which player will score the first try in a rugby league match. Another type of wager is a micro-bet, which is similar to an exotic bet, where a punter can bet on specific outcomes within a match. For example, a bet could be that a no ball will occur on the third ball of a particular over in cricket. Micro-bets give punters the chance to bet frequently and repetitively as there are usually only short periods between placing a wager and the result of a bet occurring (VRGF, 2013). Rompuy (2015) suggests that both exotic and micro-betting increase the chances of match manipulation.

The emergence of betting markets, such as 'betting exchanges', also provides punters with better odds in comparison to the predominant method of placing a wager with a bookmaker (Koning \& vanVelzen, 2009). Introduced in 2000, the concept of betting exchanges developed following a global shift to online sports betting and operates in a similar way to the stock exchange (Smith, Paton, \& Williams, 2006). Punters buy and sell bets themselves at the odds they want, effectively acting as bookmakers. For a bet to go live the offer put out by the punter needs to be matched by another user. Scant literature on betting exchanges suggests the application of a system with a strong European influence (Smith et al., 2006). As a result, it is difficult to estimate the popularity of betting exchanges within Australia given the lack of empirical research contained within the literature. 


\subsection{Sports Betting and Sport Integrity}

Despite the growth and ease of sports betting there is limited research regarding the betting habits of individuals involved in professional sport such as athletes, coaches and officials and, more specifically, those residing in Australia. Sport integrity is defined as "preserving the fundamental characteristics of sporting competition as being an honest test of skill and ability, and to act on and off the field in ways that are consistent with preserving the social and economic value of sport" (Sports Accord, 2011). Treagus, Cover, and Beasley (2011, p. 5) state that whilst there are different interpretations of "integrity" which are contingent upon context, a commonly held view suggests that integrity requires respect for "oneself and for others, and espouses moral responsibility and moral accountability." Furthermore, the integrity of sport is described as encompassing fair play, respect for the game, sportsmanship, positive personal values, compassion for others, and honesty in following rules (Treagus et al., 2011).

Accordingly, the Australian Sports Commission (ASC) (2015) argues that ethics are the fundamental component of sport integrity. Ethics guide the moral behavior and the moral values of individuals, teams and organizations in order to maintain good character (Ianinska \& Garcia-Zamor, 2006). McNamee and Fleming (2007, p. 426) profess that ethics combines principles, obligations, moral rules, agreements, and norms that individuals should follow to uphold their integrity. Similarly, Lumpkin, Stoll, and Beller (2002) state that ethics is a construct of three components: personal values of beliefs, social obligations, and professional obligations. For instance, the ethical theory of consequentialism argues that the actions of an individual are moral if their overall consequence leads to the greatest good (Rajczi, 2009). An example of this is cheating to win a sporting match; whilst winning may be seen as a good outcome for the team the act of cheating would negatively affect the team and sport itself, and therefore be an immoral act. Ethics encourages individuals to act morally and not to go against their own sense of right and wrong to achieve desired goals.

Treagus et al. (2011) argue that the underlying motivations of an individual's participation in sport impacts on sport integrity. Vallerand and Losier (1999) state that intrinsic motivation is the measure of personal satisfaction that an individual receives from participating in sport such as learning skills and accomplishing goals. In contrast, extrinsic motivation suggests that an individual's participation in sport is encouraged by external rewards such as wealth and status associated with winning. While the motivation behind amateur sport is intrinsic professional sport is increasingly shaped by extrinsic motivations (Treagus et al., 2011). Hums, Barr, and Gullion (1999) state that the ethical considerations of professional sport differ from amateur sport due to its commercialization and intent to entertain and generate income. Therefore, it is evident that the move from intrinsic motivations within amateur sport to the financial or extrinsic motivation apparent within professional sport has the potential to impact on the integrity of sporting competitions.

Influential to maintaining the integrity of a sport is its culture. The ASC (2015) proffers that a positive culture in a sport is associated with those sporting organizations that support the maintenance of integrity within their strategic framework. Culture affects all levels of the 
hierarchy within sporting organizations and is enforced by consistency in developing systems that encourage ethical values and decision-making (ASC, 2015). A positive culture towards preserving integrity is important as it sustains community confidence, trust and support of the sport. Maintaining integrity in sport has its advantages, including: increased participation and retention rates, financial sustainability increased through sporting memberships, attracting sponsors and grants, and on-field success resulting from the appeal of being associated with a successful brand (ASC, 2015).

However, a growing issue that threatens sport integrity and its commercial viability is betting-motivated corruption (McLaren, 2010). This type of corruption is motivated by gambling and involves match-fixing, spot-fixing and the exploitation of insider information. As this continues to threaten the integrity of sport, sporting organizations have feared that implementing measures against betting-motivated corruption may give rise to the notion that a gambling problem exists within the sport, thereby damaging their brand or image (McLaren, 2010). Commentary suggests that sporting organizations need to decide whether the short-term damage to their "sporting image" in acknowledging the problem early on outweighs the long-term damage betting-motivated corruption can have on sport integrity, which may include the loss of members and sporting participants, and a decline in financial support (McLaren, 2010).

\section{Corruption in Sport}

The former President of the International Olympic Committee, Jacques Rogge, stated that corruption in sport motivated by the sports betting market "...is undoubtedly the biggest threat to sport after doping" (IOC, 2010, p.1). Sport is a growth industry, generating billions of dollars in revenue and providing thousands of jobs for Australians. However, with these large profits comes the opportunity for crime and corruption. Maennig (2002, p. 62) proffers that corruption in sport involves intentional or negligent perpetration of an illicit or unethical activity, whereby a course of action is chosen by an individual that promises the greatest benefit. In extension to this definition, Maennig (2005) explained that two different types of corruption in sport exist: drug-related, which aims to win a contest or "super-perform"; and betting-motivated, which aims to "mal-perform" or play to lose. With a clear division between drug- and betting-related corruption, Boniface et al. $(2012$, p. 6) provide a more specific definition of betting-motivated corruption, stating that it involves the "manipulation or attempted manipulation of a result or aspect of a game with the aim of enrichment on the sports betting market." Much of the current literature on betting-motivated corruption in sport suggests that internationally and in Australia the predominant forms of corruption are match-fixing, spot-fixing, and the exploitation of insider information (ACC, 2013; Boniface et al., 2012).

\subsection{Common Forms of Sports Corruption}

Match-fixing involves a team or individual player playing to lose a match in order to obtain financial gain through the betting market (Gorse \& Chadwick, 2011). For example, the most prevalent match-fixing scandal in Australia involved the Victoria Premier League football team, Southern Star FC, where the abnormally poor performances by a number of the team's 
imported international players resulted in the loss of five matches in 2013 (Bricknell, 2015). These losses were linked to irregularities in the betting market, which resulted in a Hungarian and Malaysian-based Transnational Organized Crime (TOC) group profiting up to AU\$2 million (Herald Sun, 2013). Match-fixing, as claimed by Hosmer-Henner (2010), threatens the integrity of sport as spectators may believe that all matches are staged and therefore lose interest, which ultimately leads to a decline in revenue. Currently there is limited literature on the nature and extent of match-fixing in Australia; however, there have been a small number of reported cases, signifying its existence. Internationally the rise of match-fixing has gained considerable attention from both authorities and researchers. For instance Wolfers (2005), in a study into how widespread match-fixing is, found that over 16 seasons of US college basketball games $1 \%$ of games were subject to betting-motivated corruption. Similar findings were also reported by Forrest (2012), who claims that approximately $1 \%$ of all European football matches per season are affected by corruption.

Another form of corruption in sport is 'spot-fixing', which has emerged from the growth of sports betting in which technology has created an increase in the number of activities/events that a punter can now bet on within a match; it is no longer just a matter of betting on the winner. Spot-fixing occurs when a wager is placed on a specific activity/event during a match, and corrupt individuals stage this event during the game to win the bet. For example, a corrupt player could stage a no-ball in cricket during an over for the purpose of a bet (Anderson, 2011). Compared to match-fixing, this form of corruption is argued to be an increased threat to sports integrity. Rompuy $(2015$, p. 17) supports this by stating that spot-fixing is easier than fixing a match, it can be carried out by a single individual, and causes less "moral hesitancy" for the persons involved. Further to this, Rompuy also found that, in reality, spot-fixing in Europe associated with TOC groups was a decreasing risk as the market for exotic and micro-bets has low liquidity, where a large bet placed on a market with low liquidity attracts suspicion among betting regulators. However, the consequence of this is that individual players, referees and others involved in sport are at an increased risk of conducting their own spot-fixing activities. While Rompuy has examined this issue in Europe there is limited commentary regarding the nature and extent of spot-fixing in Australia.

The exploitation of insider information is also a key threat to the integrity of sport. Palmer (2014) states that individuals may have insider information on a particular subject, for example a person knowing a star player is injured and placing a large bet on the team to lose before the injury is made public. Misra, Anderson, and Saunders (2013) reported a case of using insider information for betting purposes committed by an AFL player who used club information regarding a player moving to a different position for a match, therefore increasing the likelihood of the player scoring the first goal. From the present literature on the use of insider information the majority of studies in Australia and worldwide have been on sports that are commonly bet on, such as AFL, rugby league, and cricket, rather than sports such as swimming and athletics. Furthermore, there is limited examination of the difference in exploitation of insider information between limited and highly-funded betting markets such as swimming and rugby league. 


\subsection{Sports Corruption and Illegal Bets}

Often associated with corruption in sport is the placing of illegal bets. It is estimated that approximately 8000 bookmakers form the global sports betting market, where up to $80 \%$ of these operators are located in regions with lower tax rates and limited regulation (ICSS, 2014). The consequence of this is that online bookmakers are able to create markets for sporting contests occurring anywhere in the world. An illegal bet takes place when a punter places a bet with an online bookmaker that does not have the lawful authorization to operate in the country the punter is betting from. For example, a bookmaker in China may provide live betting on Australian rugby league matches. As live betting over the Internet is banned in Australia if an Australian was to place a live bet with the Chinese bookmaker it would be classified as illegal. Within the international context, Kelly (2011) claims that in the US, where sports betting is banned in many states, $99 \%$ of bets (up to US\$380 billion per year) made on sport are illegally placed utilizing offshore gambling platforms that are in unregulated or under-regulated jurisdictions. The issue with this is that the illegal sports betting market is often linked to orchestrated activities designed to alter the odds by manipulating results through match-fixing, spot-fixing or the exploitation of insider information (Heron \& Chen, 2010). The limited amount of research on illegal betting using offshore bookmakers within Australia represents a significant gap in the literature.

\subsection{Categories of Sports Corruption}

In examining the different forms of sports corruption Boniface et al. (2012) identified three categories of corruption: corruption motivated by an individual, corruption encouraged by a club or federation, and corruption linked with TOC. Corruption motivated by an individual, such as an athlete or referee, is identified as the first stage of criminality in sport (Boniface et al., 2012). For instance, betting-motivated corruption can involve players, coaches, or referees influencing a sporting event in order to derive a financial benefit, whether it is the outcome of a match or a certain occurrence during a match (Hosmer-Henner, 2010). Corruption in sport can also stem from off-the-field activities and be influenced at a sports administration level (Boniface et al., 2012). Whilst there is scant literature on betting-motivated corruption at a club or sporting federation level within Australia there are international examples, for instance the once thriving Chinese Super League was plagued with corruption at the federation level, where competition administrators down to officials, clubs, and their players were bribed to fix matches (Hill, 2010). This led to the collapse of China's national competition as well as several other leagues in Southeast Asia (Hill, 2010).

In conducting a review of the existing knowledge on betting-motivated corruption it is evident that limited studies have been conducted surrounding the nature and extent of the phenomenon within Australia. Misra et al. (2013) suggest that further commentary on this issue should explore the vulnerabilities to such corruption and inform relevant organizations on more coordinated and effective responses within the Australian context.

\subsubsection{The Involvement of Transnational Organized Crime}

The third form of sports corruption, that relating to TOC, involves criminal activity carried 
out by structured groups of individuals in more than one country, with the aim of gaining profit through illegal means across national borders (Conklin, 2009; United Nations, 2004). A review of the literature suggests that TOC groups are heavily involved in betting-motivated corruption in sport (ACC, 2013). Through unregulated, illegal gambling and bookmaking influenced by TOC groups orchestrated activities such as match-fixing, spot-fixing, or exploiting insider information have become a threat to professional sport. The attractiveness of sport to TOC groups is explained by Etges and Sutcliffe (2008), who suggest TOC flourishes in the unregulated, decentralized environments that illegal online betting provides. Furthermore, Palmer (2014) noted that the global nature of sport and sports betting itself does not provide the geographical protection that previously protected athletes and officials. As a result, TOC groups have the ability to influence a range of sports played all over the world. For example, Misra et al. (2013) suggest that TOC groups target sub-elite-level fixtures as they are easier to exploit and are subject to less scrutiny than more heavily supported competitions.

The large profits that are generated by the sports betting industry have attracted the attention of TOC groups. For instance, large amounts of profit in excess of \$4-5 million in 90 days can be produced (Heron $\&$ Chen, 2010). In order to achieve this Hill (2008) states that the perfect conditions for fixing a match include: a reputation for honest play, poorly paid players and clubs so they can be bribed, and competitions unconcerned about corruption. Heron and Chen (2010) argue that both Australia and New Zealand are at risk of TOC groups' involvement in sport similar to what has occurred overseas. They further argue that Australia has the perfect conditions for match fixing due to the following aspects: there is a lack of financial stability amongst players and clubs, a shared time zone with Asia, a variety of different sporting competitions, and a significant growth in the Australian gambling industry. Heron and Chen (2010) further contend that in response to recent crackdowns across Europe and Asia it is evident that Asian crime syndicates and other TOC groups are likely to explore corruption sports betting activities in Australia and New Zealand.

In addition to generating enormous profits TOC groups also launder money gained from other criminal activities through sports betting platforms. The Australian Transaction Reports and Analysis Centre (AUSTRAC, 2011) argue that betting on sports is one of the most common ways to launder money. The globalization of the sports betting market has been advantageous to organized crime as it enables bets to be placed online illegally through unregulated bookmakers (Boniface et al., 2012). The outcome of this is that large amounts of money laundered through unregulated betting agencies can remain undetected. Boniface et al. (2012) note that the Albanian and Italian crime groups used similar methods, with the Italian mafia selling information regarding fixed football matches to the Albanians who would then place bets with an Albanian online sports betting site that was unregulated in Italy.

The current review suggests that commentary surrounding the involvement of TOC groups in manipulating elements of a sporting fixture is limited and the issue within Australia tends to be discussed in a broad and general context. 


\section{Theoretical Perspectives of Sports Corruption}

The existence of betting-motivated corruption can be understood using a range of academic theories, including: strain theory, contagion theory, rational choice theory, routine activity theory, and moral disengagement.

\subsection{Strain Theory}

The cause of an individual's corrupt behavior can be explained by the classical strain theory proposed by Merton (1938), who argued that the reason behind criminal behavior is due to pressures in society; in particular, the social structure of the American culture places increased importance on achieving economic stability and that an individual can either conform to this culture or deviate from the norm and attain this goal through criminal behavior. However, Agnew (1992) introduced a broader version of the classical strain theory, the general strain theory (GST). Agnew and Brezina (2010) contend that GST is a contemporary and more general approach to the classical strain theory, proposing that a broad range of strains contribute to criminal behavior. Strains can be described as situations that are disliked by an individual. There are three categories of strain: failing to attain positively valued goals, motivations that are positive, and the presentation of motivations that are negative (Agnew, 1992). Strains can intensify, negatively affecting an individual by causing them to feel anger and frustration. In order to ease these negative feelings caused by strain the individual resorts to criminal behavior because legitimate approaches fail to reinforce positive emotions. While it is evident there is an already established emphasis in the current literature on addressing adolescent criminal behavior (Baron, 2007; Ostrowsky \& Messner, 2005; Paternoster \& Mazerolle, 1994) there is a gap in knowledge surrounding the application of GST within the context of sports corruption.

\subsection{Social Contagion Theory}

Scherer and Cho (2003) suggest that social contagion involves individuals adopting the attitudes or behaviors of others in the network of people they communicate with. For example, renowned doper in cycling, Lance Armstrong, would supply banned substances to his teammates who would adopt his cheating attitude to win at no costs. If a new cyclist was to join the team they either had to adopt the same attitude as others in the team or risk being replaced (United States Anti-Doping Agency, 2012). While social contagion has been adopted to explore a range of phenomenon such as quitting smoking, obesity, suicide, and anti-social behavior (Hill, Rand, Nowak, \& Christakis, 2010), in reviewing the literature limited commentary has been conducted applying this theory within a sports corruption context.

\subsection{Rational Choice Theory (RCT)}

Rational choice theory (RCT) is a framework that involves an economic model in which individuals make decisions. Based upon the general framework of preventing crime by reducing the opportunity for it to occur, and increasing the risks associated with committing criminal behavior, the rational choice model takes into account opportunity, cost and benefit (Cornish \& Clarke, 1987). Furthermore, it is argued that RCT focuses on explaining the criminal event, while other criminological theories examine individual delinquency (Cornish 
\& Clarke, 1987). Piliavin, Gartner, Thornton, and Matsueda (1986) suggest that, by applying RCT to criminal activity, if the expected benefit of an illegal act is greater than its alternatives then the individual will engage in crime. Piliavin et al. (1986) claim that the benefit of a considered activity takes into account three elements: the likelihood of being punished, the expected returns, and the likely penalty if the individual was punished for the activity. RCT has been applied to examine a broad range of criminal offences such as traffic offences (Corbett \& Simon, 1992), white-collar crime (Piquero, Exum, \& Simpson, 2005), and theft and violence (Matsueda, Kreager, \& Huizinga, 2006). Preston and Szymanski (2003) demonstrated the application of RCT to the issue of match-fixing; however, further contribution needs to be made to the existing knowledge in understanding the nature of sports corruption from an RCT perspective.

\subsection{Routine Activity Theory (RAT)}

The routine activity theory (RAT) is an opportunity-based framework that suggests that a crime occurs when the following three factors exist: a motivated offender, who is the individual looking to commit a crime; the availability of a suitable target, which is the "thing" the motivated offender is aiming for; and the absence of a capable guardian, who is any person or object which acts as a crime deterrent (Cohen \& Felson, 1979). According to RAT, crime occurs when a motivated offender and a suitable target come together in space and time while in the absence of a capable guardian (Cohen \& Felson, 1979). Peurala (2013) examined betting-motivated corruption in sport and illegal betting through the RAT perspective. A motivated offender has a range of opportunities through online sports betting, where the risk of getting caught can increase when a match is fixed and a noticeable bet is made using a regulated bookmaker in the same jurisdiction. However, the risk of being caught decreases when a bet is placed with an unregulated bookmaker on a fixed match (Peurala, 2013). However, while there is existing literature examining RAT against a range of different crimes there is limited discussion surrounding its application in understanding sports corruption.

\subsection{Moral Disengagement}

Moral disengagement is a theory of moral behavior influenced by Bandura's (1991) eight psychosocial mechanisms. Bandura (1991) states that moral disengagement occurs when an individual chooses to oppose their moral standards, which would normally deter them from wrong-doing, by disengaging from their own feeling of guilt when breaching individual moral standards. For instance, moral disengagement has been linked with behavior involving the violation of moral and social boundaries, and antisocial behavior (Bandura, Caprara, Barbaranelli, Pastorelli, \& Regalia, 2001). In support of this notion, Moore (2007) states that research surrounding moral disengagement has been largely theoretical, exploring issues surrounding anti-social behavior among young people.

However, there are a range of studies exploring moral disengagement to gain a greater understanding of corruption in sport. In a review conducted by Boardley and Kavussanu (2011), they argue that the existing literature on moral disengagement in sport investigates behaviors that occur during sport participation, and the relationship between moral disengagement and doping. For example, Long, Pantaleon, Bruant, and d'Arripe-Longueville 
(2006) found that moral disengagement occurred when an authority figure, such as a coach, instructs an athlete or team to do something; the athlete or team absolve themselves of responsibility and do whatever they are instructed to do. Similar conclusions were drawn by Traclet, Romand, Moret, and Kavussanu (2011), who found that soccer players placed the responsibility of their antisocial actions, such as aggression or cheating, on the referee due to bad officiating, or they displaced their responsibility to their coach and teammates. In reviewing the existing literature it is evident that moral disengagement can provide greater understanding of a wide range of corruption-related contexts.

\section{Anti-Corruption in Sport: Prevention and Enforcement}

Misra et al. (2013) argue that the prevention and enforcement of betting-motivated corruption in sport requires a nationally co-ordinated anti-corruption strategy. In an evaluation of the anti-corruption approach in Finland Peurala (2013) identified a lack of knowledge on match-fixing within Finland, absence of match-fixing in the criminal code, and the nonexistence of a nationally co-ordinated anti-corruption strategy. This same suggestion was made by Sportsradar (2014), who recommend a coordinated approach involving inter-agency collaboration between sporting bodies, law enforcement agencies, and betting regulators.

\subsection{National Match-fixing Policy}

In Australia the National Policy on Match-fixing in Sport was introduced in 2011 by the federal government, along with a non-regulatory body called the National Integrity in Sport Unit (NISU). NISU provides oversight, monitoring, and coordination of anti-corruption efforts in Australian sport (NISU, 2015). The policy is a national anti-corruption strategy that aims to maintain integrity in sport by encouraging a coordinated effort between sporting bodies, law enforcement agencies, and betting regulators. The policy also aims to ensure consistency across Australia with respect to legislation targeting match-fixing and that there are national standards which are applied to governing bodies, sporting organizations, and the betting industry (NISU, 2015). It is evident that Australia is committed to a coordinated, inter-agency approach to address the issue of match-fixing in sport. However, it is unknown if the policy is effective, and there is no clear suggestion of TOC being included within its scope. Furthermore, there is limited commentary on what penalties are applied to athletes, coaches, support staff and other key stakeholders involved in betting-motivated corruption at a sporting organization level.

\subsection{Prevention at the Sporting Organization Level}

Boniface et al. (2012) argue that maintaining the integrity of sport starts with the prevention of corruption at the sporting organization level. Sporting organizations such as federations, clubs, and associations are responsible for athletes, coaches, support staff, and officials. Three central elements exist in preventing betting-motivated corruption: education, investigation, and sanctioning. Drawing upon the approach of the highly regulated horse racing industry, Anderson (2011) argues that educational programs, codes of conduct, moral clauses in contracts, anti-corruption investigation units, and strict and lengthy sanctions are all fundamental in effective anti-corruption policy of sport governing bodies. However, 
Transparency International (2014), in a pilot study on match-fixing in European football, identified "awareness" and "educational programs" as key to addressing the problem of match-fixing in Europe. The same view was also identified by Abbott and Sheehan (2013), and Forrest (2012), who contend that the fundamental elements of effective prevention include awareness, education and training aimed at increasing an individual's knowledge of the consequences of betting-motivated corruption. It is evident that education is important in addressing sport corruption; however, it should also be supported by codes of conduct and other measures developed through good governance.

In examining the current literature on the prevention of sports betting-motivated corruption it is evident that good governance within sporting organizations is necessary in addressing the issue of corruption (Abbott \& Sheehan, 2013; Forrest, 2012; Transparency International, 2012). For instance, sports betting-motivated corruption plagued Chinese football at all levels of the organizational hierarchy as a result of poor governance (Hill, 2008). Transparency International (2014) suggest that current governance practices in sport need to change, such as improving transparency by increasing the information publicly shared about organizational activities and decisions. A lack of transparency and oversight within a sporting body increases the chances of corruption (Transparency International, 2014). Good governance also encompasses promoting values against sports betting-motivated corruption, as well as the inclusion of anti-corruption provisions within codes of conduct (Transparency International, 2014).

In the Australian context, Gleeson (2011) identified varying results in terms of integrity procedures; while some sporting bodies responded proactively with modifications to their codes of conduct and educational programs others were more reactive in their approach, which saw changes in processes and integrity methods only coming into effect if a breach occurred (Gleeson, 2011). It is apparent that limited literature exists surrounding the perceptions of individuals affected by processes and integrity methods administered by Australian sporting organizations. Furthermore, a gap in the literature exists surrounding the effectiveness of anti-corruption strategies within sporting organizations in Australia.

\subsection{Betting Regulators}

Within the existing literature researchers have argued for a ban on sports betting to prevent sports corruption. The negative impact of this was identified by Kelly (2011), where, to address the issue of match-fixing, the prohibition of sports betting in the US generated an increased use of offshore online bookmakers operating within illegal betting markets. The implications of this ban were also explained by Hosmer-Henner (2010), who suggested that prohibiting sports betting in one jurisdiction forced punters to access bookmakers in other jurisdictions outside the authority of betting regulators. The advantage of a regulated system is that licensed bookmakers are able to effectively identify and report irregular betting patterns to the necessary agencies (Forrest, 2008), which often indicates corruption in sport, such as match-fixing and spot-fixing. Regulated systems ensure that the integrity of sport is maintained, but also prevent the bookmaker from losing money. For example, in Australia, Forrest (2008) reports that an agreement was introduced in 2006 where bookmaker Betfair 
and Cricket Australia would share revenue and detect irregularities in the betting market. Overall, the literature suggests that the prohibition of sports betting does not properly address the issue of corruption in sport.

While strict regulation of betting operators is suggested there is only so much that can be done before perpetrators will place a bet through online bookmakers in unregulated countries. Forrest (2008) suggests that an international approach to regulating the sports betting market would be more effective due to the globalization of online betting. The ICSS (2014) states that betting regulatory frameworks have not developed at a rate concurrent with the growth of the global online sports betting market. The majority of national betting regulators are poorly resourced and inexperienced in conducting effective surveillance, monitoring, and analysis of the betting market for irregular activity that may indicate the manipulation of sporting matches and money laundering (ICSS, 2014). In reviewing existing knowledge surrounding the regulation of sports betting the question is whether betting regulators are effective in their detection of irregular patterns and if these irregularities are promptly reported to the appropriate sporting bodies.

\subsection{Law Enforcement}

The detection and enforcement of sports betting-motivated corruption can be carried out by either an anti-corruption body or law enforcement agency (Ramos, 2009). Heron and Chen (2010) and Transparency International (2008) state that the best method to address betting-motivated corruption is to adopt a standardized and harmonized regime. This is evidenced by the creation of the World Anti-Doping Code, which is enforced by the World Anti-Doping Agency (WADA). Heron and Chen argue that the advantages of implementing a government-run, uniform, anti-corruption body include greater financial stability, and investigative and enforcement powers. However, the issue with developing a global anti-corruption body against betting-motivated corruption is challenged by Forrest (2008), who argues that gaining international cooperation takes time, and that the most effective measure of anti-corruption against sports corruption starts with sporting organizations themselves.

In Australia the ACC (2013) state the resources dedicated to managing threats to the integrity of sport in Australia have not grown at the same pace as the sports betting industry. For instance, the law enforcement response to betting-motivated corruption within Australia and worldwide has traditionally been dealt with reactively and with little urgency as opposed to other TOC issues, such as drug importation (Misra et al., 2013). However, while still playing catch-up, the approach towards preventing betting-motivated corruption has significantly changed, with law enforcement agencies moving towards a more proactive method in addressing the issue. For instance, Bricknell (2015) states that a limited number of specialized sports intelligence units have been set up in Australia. At a state level the Victoria Police established the Sport Integrity Intelligence Unit in 2013, while the New South Wales Police Force established the Casino and Racing Investigation Unit; however, they focus mainly on race-fixing in horse and greyhound racing. Bricknell (2015) also reports that the Australian Federal Police and ACC have an interest in sports corruption. 
This review highlights the limited empirical research regarding the extensiveness of the law enforcement effort in Australia; however, this could be due to the limited number of specialized units developed to address sport corruption.

\section{Conclusion}

A review of the literature has highlighted various themes surrounding sports betting-motivated corruption. The sports betting industry has evolved exponentially since the development of the Internet, which has brought about the development of a readily accessible global market that exploits interactive media devices. A targeted marketing strategy by the industry, including sport sponsorship, has led to it becoming an integral part of the spectator experience. Commentary on the importance of integrity in preserving the economic and social value of sport has been examined, as well as how sport integrity is under threat by corrupt practices motivated by the sports betting market. The literature review examined the different forms of betting motivated corruption, in particular: match-fixing, spot-fixing, and the exploitation of insider information. These forms can be instigated by an individual, club, federation, or TOC group. Five predominant academic theories in sports corruption - strain theory, contagion theory, rational choice theory, routine activity theory, and moral disengagement-have been shown to provide a theoretical platform to examine the phenomenon of betting-motivated corruption. This review also examined commentary surrounding the benefits of employing a coordinated multi-agency response comprising of sporting organizations, betting regulators, and law enforcement, to combat the threat of betting-motivated corruption.

However, despite the many theories available through which to examine and understand sports betting-motivated corruption what this review highlights is that more research is needed to better understand the nature and extent of the phenomenon worldwide and, in particular, throughout Australia. With gambling firmly embedded in Australian culture, the dearth of research on the phenomenon in an Australian context and the continuing growth of online, interactive gambling opportunities, there is a need to better understand current anti-corruption measures, and the effectiveness of these anti-corruption strategies in addressing the threat of betting-motivated corruption in Australian sport.

\section{Acknowledgements}

The authors acknowledge the support provided by the Queensland Academy of Sport Centre of Excellence for Applied Sport Science Research.

\section{References}

Abbott, J., \& Sheehan, D. (2013). The interpol approach to tackling match fixing in football. In M. Haberfeld \& D. Sheehan (Eds.), Match-fixing in international sports: Existing processes, law enforcement, and prevention strategies (pp. 263-287). Switzerland: Springer International Publishing. http://dx.doi.org/10.1007/978-3-319-02582-7_14

ACC. (2013). Threats to the integrity of professional sport in Australia. Retrieved from https:/www.crimecommission.gov.au/sites/default/files/Threat $\% 20 \mathrm{~s} \% 20$ to $\% 20$ the $\% 20$ integri 
ty\%20of\%20professional\%20sport\%20in\%20Australia\%20JULY\%202013.pdf

Agnew, R. (1992). Foundation for a general strain theory of crime and delinquency. Criminology (Beverly Hills), $\quad 30(1), \quad$ 47-88. http://dx.doi.org/10.1111/j.1745-9125.1992.tb01093.x

Agnew, R., \& Brezina, T. (2010). Strain theories. In E. McLaughlin \& T. Newburn (Eds.), The SAGE handbook of criminological theory (pp. 96-113). London: SAGE Publications Ltd. http://dx.doi.org/10.4135/9781446200926.n6

Anderson, J. (2011). Combating serious crime and corruption in sport: International and Comparative perspectives workshop. Retrieved from http://www.ceps.edu.au/CMS/Uploads/file/Jack\%20Anderson.pdf

ASC. (2015). What is sport integrity. Retrieved from http://www.ausport.gov.au/supporting/integrity_in_sport/about/what_is_sport_integrity

AUSTRAC. (2011). Money laundering in Australia 2011. Retrieved from http://www.austrac.gov.au/sites/default/files/documents/money_laundering_in_australia_2011 .pdf

Bandura, A. (1991). Social cognitive theory of moral thought and action. In W. Kurtines \& J. Gewirtz (Eds.), Handbook of moral behaviour and development: Theory research and applications (pp. 101-119). Hillsdale, NJ: Lawrence Erlbaum Associates.

Bandura, A., Caprara, G., Barbaranelli, C., Pastorelli, C., \& Regalia, C. (2001). Socio-cognitive self-regulatory mechanisms governing transgressive behaviour. Journal of $\begin{array}{llrr}\text { Personality and Social Pychology, } & 80(1), & 125-135 .\end{array}$ http://dx.doi.org/10.1037//0022-3514.80.1.125

Baron, S. W. (2007). Street youth, gender, financial strain, and crime: Exploring Broidy and Agnew's extension to general strain theory. Deviant Behavior, 28(3), 273-302. http://dx.doi.org/10.1080/01639620701233217

Boardley, I. D., \& Kavussanu, M. (2011). Moral disengagement in sport. International Review of Sport and Exercise Psychology, 4(2), 93-108. http://dx.doi.org/10.1080/1750984X.2011.570361

Boniface, P., Lacarriere, S., Verschuuren, P., \& Tuallon, A. (2012). Sports betting and corruption: How to preserve the integrity of sport. Retrieved from http://www.sportaccord.com/multimedia/docs/2012/02/2012_-_IRIS_-_Etude_Paris_sportifs_ et_corruption_-_ENG.pdf

Bricknell, S. (2015). Corruption in Australian sport. Woden: Australian Institute of Criminology.

Cohen, L., \& Felson, M. (1979). Social change and crime rate trends: A routine activity approach. American Sociological Review, 44(4), 588-608. http://dx.doi.org/10.2307/2094589

Conklin, J. (2009). Criminology (Vol. 10). Boston: Pearson. 
Corbett, C., \& Simon, F. (1992). Decisions to break or adhere to the rules of the road, viewed from the rational choice perspective. The British Journal of Criminology, 32(4), 537-549. http://dx.doi.org/10.2307/23638323

Cornish, D., \& Clarke, R. (1987). Understanding Crime Displacement: An Application of Rational Choice Theory. Criminology, 25(4), 933-948. http://dx.doi.org/10.1111/j.1745-9125.1987.tb00826.x

Delfabbro, P., \& King, D. (2012). Gambling in Australia: experiences, problems, research and policy. Addiction, 107(9), 1556-1561. http://dx.doi.org/10.1111/j.1360-0443.2012.03802.x

Etges, R., \& Sutcliffe, E. (2008). An overview of transnational organized cyber crime. Information Security Journal: A Global Perspective, 17(2), 87-94. http://dx.doi.org/10.1080/19393550802036631

Forrest, D. (2008). Say it ain't so: Betting-related malpractice in Sport. Sport Finance, 3(3), 156-166.

Forrest, D. (2012). The threat to football from betting-related corruption. International Journal of Sport Finance, 7(1), 99-116.

Forrest, D., \& Simmons, R. (2003). Sport and gambling. Oxford Review of Economic Policy, 19(4), 598-611. http://dx.doi.org/10.1093/oxrep/19.4.598

Gainsbury, S. M. (2014). Interactive gambling. Retrieved from https://www3.aifs.gov.au/agrc/publications/interactive-gambling/rise-interactive-gambling

Gainsbury, S. M., Russell, A., Hing, N., Wood, R., Lubman, D., \& Blaszczynski, A. (2015). How the Internet is changing gambling: Findings from an Australian prevalence survey. Journal of Gambling Studies, 31(1), 1-15. http://dx.doi.org/10.1007/s10899-013-9404-7

George, S., \& Chima, C. (2014). Gambling addiction: What every doctor needs to know. Internet Journal of Medical Update, 9(1), 1-3.

Gleeson, D. (2011). Review of sports betting regulation. Retrieved from http://www.justice.vic.gov.au/home/justice+system/laws+and+regulation/sports+betting + revi ew+-+report+and+government+response

Gorse, S., \& Chadwick, S. (2011). The prevalence of corruption in international sport: A statistical analysis. Retrieved from http://www.rga.eu.com/data/files/Press2/corruption_report.pdf

Herald, S. (2013). Police arrest coach, nine players in $\$ 2$ million match-fixing probe. Retrieved from http://www.heraldsun.com.au/news/law-order/police-arrest-coach-nine-players-in-2-millionmatchfixing-probe/story-fni0fee2-1226719446123

Heron, M., \& Chen, J. (2010). The gathering storm-organised crime and sports corruption. Australian and New Zealand Sports Law Journal, 5(1), 99-118. 
Hill, A., Rand, D., Nowak, M., \& Christakis, N. (2010). Infectious disease modeling of social contagion in networks. PLOS Computational Biology, 6(11), 1-15. http://dx.doi.org/10.1371/journal.pcbi. 1000968

Hill, D. (2008). The fix: Soccer and organised crime. Toronto: McClelland and Stewart.

Hill, D. (2010). A critical mass of corruption: Why some football leagues have more match-fixing than others. International Journal of Sports Marketing and Sponsorship, 11(3), 221-235.

Hing, N., Vitartas, P., \& Lamont, M. (2013). Gambling sponsorship of sport: An exploratory study of links with gambling attitudes and intentions. International Gambling Studies, 13(3), 281-301. http://dx.doi.org/10.1080/14459795.2013.812132

Hosmer-Henner, A. (2010). Preventing game fixing: Sports books as information markets. Gaming Law Review and Economics, 14(1), 31-38. http://dx.doi.org/10.1089/glre.2010.14107

Humphreys, B. (2011). Online sports betting and international relations. The SAIS Review of International Affairs, 31(1), 103-115. http://dx.doi.org/10.1353/sais.2011.0009

Hums, M., Barr, C., \& Gullion, L. (1999). The Ethical issues confronting managers in the sport industry. Journal of Business Ethics, 20(1), 51-66. http://dx.doi.org/10.1023/A:1005951720456

Ianinska, S., \& Garcia-Zamor, J. C. (2006). Morals, ethics, and integrity: How codes of conduct contribute to ethical adult education practice. Public Organization Review, 6(1), 3-20. http://dx.doi.org/10.1007/s11115-006-6831-2

International Centre for Sport Security (ICSS). (2014). Protecting the integrity of sport competition. $\quad$ Retrieved from http://www.theicss.org/wp-content/themes/icss-corp/pdf/SIF14/Sorbonne-ICSS\%20Report\%2 0Executive\%20Summary_WEB.pdf

International Olympic Committee (IOC). (2010). Sports movement agrees on unified strategy to tackle irregular betting. Retrieved from http://www.olympic.org/content/press-release/press-release-pr43-2010/

Kelly, J. (2011). Sports wagering prohibition in the United States: An exercise in futility and the best development for organised crime. Gaming Law Review and Economics, 15(5), 257-259. http://dx.doi.org/10.10.89/glre.2011.15508

Koning, R., \& vanVelzen, B. (2009). Betting exchanges: The future of sports betting? International Journal of Sport Finance, 4(1), 42-62.

Long, T., Pantaleon, N., Bruant, G., \& d'Arripe-Longueville, F. (2006). A qualitative study of moral reason of young elite athletes. The Sport Psychologist, 20(3), 330-347.

Lumpkin, A., Stoll, S., \& Beller, J. (2002). Sport Ethics: Applications for Fair Play (3rd ed.). New York: McGraw Hill. 
Maennig, W. (2002). On the economics of doping and corruption in international sports. Journal of Sports Economics, 3(1), 61-89. http://dx.doi.org/10.1177/1527002502003001005

Maennig, W. (2005). Corruption in international sports and sport management: forms, tendencies, extent and countermeasures. European Sport Management Quarterly, 5(2), 187-225. http://dx.doi.org/10.1080/16184740500188821

Maher, A., Wilson, N., Signal, L., \& Thomson, G. (2006). Patterns of sports sponsorship by gambling, alcohol and food companies: An Internet survey. BMC Public Health, 6(1), 95. http://dx.doi.org/10.1186/1471-2458-6-95

Mason, K. (2005). How corporate sponsorship impacts consumer behaviour. Journal of American Academy of Business, 7, 32 - 35.

Matsueda, R. L., Kreager, D. A., \& Huizinga, D. (2006). Deterring delinquents: A rational choice model of theft and violence. American Sociological Review, 71(1), 95-122. http://dx.doi.org/10.1177/000312240607100105

McLaren, R. (2010). Is sport losing its integrity? Sports Law Review, 551.

McMullan, J., Miller, D., \& Perrier, D. (2012). "I've seen them so much they are just there": Exploring young people's perceptions of gambling in advertising. International Journal of Mental Health and Addiction, 10(6), 829-848. http://dx.doi.org/10.1007/s11469-012-9379-0

McNamee, M., \& Fleming, S. (2007). Ethics audits and corporate governance: The case of public sector sports organizations. Journal of Business Ethics, 73(4), 425-437. http://dx.doi.org/10.1007/s10551-006-9216-0

Merton, R. K. (1938). Social structure and anomie. American Sociological Review, 3(5), 672-682. http://dx.doi.org/10.2307/2084686

Milner, L., Hing, N., Vitartas, P., \& Lamont, M. (2013). Embedded gambling promotion in Australian Football broadcasts: An exploratory study. Communication, Politics \& Culture, 46(1), 177-198.

Misra, A., Anderson, J., \& Saunders, J. (2013). Safeguarding sports integrity against crime and corruption: An Australian perspective. In M. Haberfeld \& D. Sheehan (Eds.), Match-fixing in international sports: Existing processes, law enforcement and prevention strategies (pp. 135-155). Switzerland: Springer International Publishing. http://dx.doi.org/10.1007/978-3-319-02582-7_8

Moore, C. (2007). Moral Disengagement in Processes of Organizational Corruption. Journal of Business Ethics, 80(1), 129-139. http://dx.doi.org/10.1007/s10551-007-9447-8

NISU. (2015). National Integrity of Sport Unit. Retrieved from http://www.health.gov.au/internet/main/publishing.nsf/Content/national-integrity-of-sport-uni $\mathrm{t}$

Ostrowsky, M. K., \& Messner, S. F. (2005). Explaining crime for a young adult population: An application of general strain theory. Journal of Criminal Justice, 33(5), 463-476. 
http://dx.doi.org/10.1016/j.jcrimjus.2005.06.004

Palmer, B. (2014). Sports betting research: Literature review. Retrieved from http://www.dhhs.tas.gov.au/_data/assets/pdf_file/0006/170772/Sports_Betting_Literature_R eview.pdf

Paternoster, R., \& Mazerolle, P. (1994). General strain theory and delinquency: A replication and extension. Journal of Research in Crime and Delinquency, 31(3), 235-263. http://dx.doi.org/10.1177/0022427894031003001

Peurala, J. (2013). Match-manipulation in football - the challenges faced in Finland. The International Sports Law Journal, 13(3-4), 268-286. http://dx.doi.org/10.1007/s40318-013-0027-z

Piliavin, I., Gartner, R., Thornton, C., \& Matsueda, R. (1986). Crime, deterrence, and rational choice. American Sociological Review, 51(1), 101-119. http://dx.doi.org/10.2307/2095480

Pinto, S., \& Wilson, P. (1990). Gambling in Australia. Retrieved from http://www.aic.gov.au/documents/A/A/2/\%7BAA236B7C-0159-4A84-8F90-C74158D97540 $\% 7$ Dti24.pdf

Piquero, N. L., Exum, L., \& Simpson, S. (2005). Integrating the desire-for-control and rational choice in a corporate crime context. Justice Quarterly, 22(2), 252-280. http://dx.doi.org/10.1080/07418820500089034

Preston, I., \& Szymanski, S. (2003). Cheating in contests. Oxford Review of Economic Policy, 19(4), 612-624. http://dx.doi.org/10.1093/oxrep/19.4.612

Productivity Commission. (2010). Gambling. Retrieved from http://www.pc.gov.au/inquiries/completed/gambling-2009/report/gambling-report-volume1.p df

Rajczi, A. (2009). Consequentialism, integrity, and ordinary morality. Utilitas, 21(03), 377. http://dx.doi.org/10.1017/S0953820809990112

Ramos, M. (2009). Game, set, match-fixing: Will international anti-doping initiatives pave the way for similar reform for corrupt betting in tennis? Houston Journal of International Law, 32(1), 201-244.

Reiche, D. (2013). The prohibition of online sports betting: A comparative analysis of Germany and the United States. European Sport Management Quarterly, 13(3), 293-314. http://dx.doi.org/10.1080/16184742.2012.741140

Rompuy, B. V. (2015). The odds of match fixing: Facts and figures on the integrity risk of $\begin{array}{llll}\text { certain } & \text { bets. } & \text { Retrieved }\end{array}$ http://www.asser.n1/media/2422/the-odds-of-matchfixing-report2015.pdf

Scherer, C., \& Cho, H. (2003). A social network contagion theory of risk perception. Risk Analysis, 23(2), 261-268. http://dx.doi.org/10.1111/1539-6924.00306 
Schnytzer, A., \& Weinberg, G. (2008). Testing for home team and favorite biases in the Australian rules football fixed-odds and point spread betting markets. Journal of Sports Economics, 9(2), 173-190. http://dx.doi.org/10.1177/1527002506299079

Smith, M., Paton, D., \& Williams, L. (2006). Market efficiency in person-to-person betting. Economica, 73(292), 673-689.

SportsAccord. (2011). Model rules: On sports integrity in relation to sports betting for all international sports federations and organisations. Retrieved from http://www.sportaccord.com/multimedia/docs/2011/08/Model_Rules_on_Sports_Integrity_in _Relation_to_Sports_Betting.pdf

Sportsradar. (2014). World match-fixing-the problem and the solution. Retrieved from https://security.sportradar.com/wp-content/uploads/sites/6/2014/12/Sportradar-Security-Servi ces_World-Match-Fixing-The-Problem-and-the-Solution1.pdf

The Economist. (2014). Who gambles the most? Retrieved from http://www.economist.com/blogs/graphicdetail/2014/02/daily-chart-0

Thomas, S., Lewis, S., Duong, J., \& McLeod, C. (2012). Sports betting marketing during sporting events: a stadium and broadcast census of Australian Football League matches. Aust N Z J Public Health, 36(2), 145-152. http://dx.doi.org/10.1111/j.1753-6405.2012.00856.x

Traclet, A., Romand, P., Moret, O., \& Kavussanu, M. (2011). Antisocial behavior in soccer: A qualitative study of moral disengagement. International Journal of Sport and Exercise Psychology, 9(2), 143-155. http://dx.doi.org/10.1080/1612197X.2011.567105

Transparency International. (2008). Why sport is not immune to corruption. Retrieved from http://www.coe.int/t/dg4/epas/Source/Ressources/EPAS_INFO_Bures_en.pdf

Transparency International. (2012). Tackling match fixing needs good governance. Retrieved from http://blog.transparency.org/2012/09/24/tackling-match-fixing-needs-good-governance

Transparency International. (2014). Staying on side: How to stop match-fixing. Retrieved rom http://www.transparency.org/whatwedo/publication/staying_on_side_how_to_stop_match_fix ing

Treagus, M., Cover, R., \& Beasley, C. (2011). Integrity in sport literature review. Retrieved from

http://www.ausport.gov.au/_data/assets/pdf_file/0011/516782/Integrity_in_Sport_Literature _Review-.pdf

Tse, S., Dyall, L., Clarke, D., Abbott, M., Townsend, S., \& Kingi, P. (2012). Why people gamble: a qualitative study of four New Zealand ethnic groups. International Journal of Mental Health and Addiction, 10(6), 849-861. http://dx.doi.org/10.1007/s11469-012-9380-7

United Nations. (2004). United Nations Convention against Transnational Organized Crime. Retrieved from http://www.unodc.org/documents/middleeastandnorthafrica/organised-crime/UNITED_NATI 
ONS_CONVENTION_AGAINST_TRANSNATIONAL_ORGANIZED_CRIME_AND_TH E_PROTOCOLS_THERETO.pdf

United States Anti-Doping Agency. (2012). U.S. postal service pro cycling team investigation. Retrieved from http://cyclinginvestigation.usada.org/

Vallerand, R. J., \& Losier, G. F. (1999). An integrative analysis of intrinsic and extrinsic motivation in sport. Journal of Applied Sport Psychology, 11(1), 142-169. http://dx.doi.org/10.1080/10413209908402956

VRGF. (2013). What is sports betting. Retrieved from http://www.responsiblegambling.vic.gov.au/_data/assets/pdf_file/0005/3938/What-is-Sports -Betting.pdf

Wolfers, J. (2005). Point shaving: Corruption in NCAA Basketball. The American Economic Review, 96(2), 279-283. http://dx.doi.org/10.1257/000282806777211757

Worthington, A., Brown, K., Crawford, M., \& Pickernell, D. (2007). Gambling participation in Australia: Findings from the national Household Expenditure Survey. Review of Economics of the Household, 5(2), 209-221. http://dx.doi.org/10.1007/s11150-007-9006-1

\section{Copyright Disclaimer}

Copyright for this article is retained by the author(s), with first publication rights granted to the journal.

This is an open-access article distributed under the terms and conditions of the Creative Commons Attribution license (http://creativecommons.org/licenses/by/3.0/). 